\title{
Análise comparativa de envoltórios para drenos tubulares em condições de fluxo não-permanente ${ }^{1}$
}

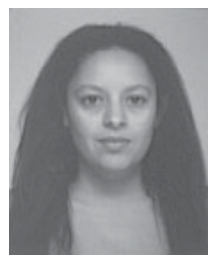

Denise M. de Almeida ${ }^{2}$, Raimundo N.T. Costa ${ }^{3}$, Luis C.U. Saunders ${ }^{3}$ \& José Matias Filho ${ }^{4}$

\author{
1 Parte da Dissertação de Mestrado apresentada pelo primeiro autor à UFC \\ 2 R. Gonçalves Ledo 10/610, CEP 60110-260, Fortaleza,CE. Fone: (85) 219-1808 (Foto) \\ ${ }^{3}$ DENA/CCA/UFC, Campus do Pici, Bloco 804, CEP 60455-760, Fortaleza, CE. Fone: (85) 288-9765. E-mail: rntcosta@ufc.br \\ ${ }^{4}$ CCA/UFC. Fortaleza, CE. Fone: (85) 234-7128
}

Protocolo $025-16 / 03 / 2000$

\begin{abstract}
Resumo: Com esta pesquisa, objetivou-se avaliar a eficiência de envoltórios em drenos tubulares sob condições de fluxo não-permanente; para tanto, foram utilizados, em tanques de alvenaria, os envoltórios de geotêxteis XT-4, XT-2, bidim OP-30 e bidim OP-20, envelopes de brita $n^{\circ} 1$, com espessuras de $0,05,0,10$ e $0,15 \mathrm{~m}$, além de um tratamento com ausência de envoltório. As variáveis-resposta utilizadas para se testar os tratamentos consistiram da lâmina drenada num tempo de 30 min, da massa de areia carreada após este tempo de drenagem e do desempenho hidráulico dos drenos, com base no cálculo da resistência de entrada ao fluxo e da relação entre vazão e carga hidráulica a 0,55 m da interface solo-dreno. As lâminas drenadas não diferiram estatisticamente a nível de $5 \%$ de probabilidade; no entanto, os geotêxteis bidim OP-20 e XT-4 mostraram-se, nesta ordem, como as melhores opções, face à análise de desempenho e se considerando os aspectos custo e facilidade de instalação. Quanto à análise da variável carreamento de areia, verificou-se a influência da espessura do envoltório ao se analisar os tratamentos com brita, além da opção das mantas, como excelente filtro. Os dados de resistência de entrada demonstraram a importância do uso de envoltórios ao se comparar o tratamento sem envoltório $\left(r_{\text {ent }}=0,0102 \mathrm{~d} \mathrm{~m}^{-1}\right)$ com o tratamento brita $0,15 \mathrm{~m}\left(r_{\text {ent }}=0,0032 \mathrm{~d} \mathrm{~m}^{-1}\right)$ cuja redução foi de $68,7 \%$.
\end{abstract}

Palavras-chave: drenagem, desempenho, envoltório

\section{Comparative analysis of envelopes for tubular drains under non-steady state flow conditions}

\begin{abstract}
The aim of the research was to evaluate the performance of eight types of envelopes installed around tubular drains in a horizontal tank model, with the treatments bidim OP-20, bidim OP-30, XT-2 and XT-4, 0.15, 0.10 and $0.05 \mathrm{~m}$ thick gravel and the treatment drain without a wrapper. The response-variables for the treatments used consisted of the depth of water drained in thirty minutes, the mass of sediment transported by the water during this same time interval and the hydraulic performance of the drains based on the entrance resistance of the flow and relation between the flowrate and the hydraulic head at $0.55 \mathrm{~m}$ drain-soil. The depth of water drained did not show significant difference at $5 \%$ probability level; however, the geotextile bidim OP-20 and XT-4 showed the best performance taking into account costs and instalation suitability. In relation to the sediment mass transported, the influence of the wrapper thickness using gravel was observed besides the option of geotextile as excelent filter. The importance of using drain wrappers was demonstrated by comparing the entrance resistance data for the treatments without wrapper $\left(r_{\text {ent }}=0.0102 \mathrm{~d} \mathrm{~m}^{-1}\right)$ and the $0.15 \mathrm{~m}$ gravel treatment $\left(r_{\text {ent }}=0.0032 \mathrm{~d} \mathrm{~m}^{-1}\right)$, allowing a $68.7 \%$ reduction.
\end{abstract}

Key words: drainage, performance, envelope

\section{INTRODUÇÃO}

Em excesso no solo, a água pode bloquear o processo de aeração e comprometer, desta forma, o desenvolvimento das raízes. A drenagem artificial é, muitas vezes, necessária, não apenas para melhorar a aeração do solo mas, também, para facilitar a remoção dos sais solúveis e impedir a sua acumulação em níveis tóxicos às plantas. Em muitas regiões, sem a drenagem torna-se impossível a remoção do excesso de sais e, por conseqüência, o melhoramento do solo (Hillel, 1970).

A drenagem agrícol consiste na retirada do excesso de água do solo a uma taxa q ıe permita uma exploração econômica das culturas e a utilizaçâo da área, por longo tempo. As áreas relativamente planas, qu ocupam posição baixa no relevo, são usualmente as mais fáce de se cultivar e irrigar, apresentando alto potencial agrícola no regiões áridas e semi-áridas, como o 
Nordeste brasileiro, porém a maioria dessas áreas está sujeita ao processo de salinização do solo, quando os sistemas de irrigação são implantados e manejados de forma inadequada. Daí por que a instalação e a manutenção de sistemas de drenagem assumem importância fundamental. Em regiões de clima úmido, a elevação do lençol freático ocorre na estação chuvosa, dadas as precipitações mais intensas. $\mathrm{O}$ excesso de água no solo, devido aos altos níveis estacionais ou periódicos do lençol freático, tem-se constituído no principal risco para limitar a produtividade das culturas.

Conforme Lamster (1980) as áreas de várzeas no Brasil abrangem um total de 30 milhões de hectares. Qualitativamente, os solos dessas áreas, por suas características físico-químicas e condições topográficas aliadas às técnicas de drenagem e irrigação, representam grande potencial para o incremento da produção agrícola. Ainda conforme o autor, a técnica de drenagem pode ser utilizada por meio de drenos abertos ou drenos cobertos dependendo, sobretudo, das condições de estabilidade do solo, em que cada variante tem suas vantagens e limitações específicas; no entanto, o potencial de utilização de drenos cobertos, levando-se em consideração unicamente as condições de estabilidade do solo, é muito grande pois, tendo em vista aspectos relacionados ao desempenho, à vida útil e pouca necessidade de manutenção, os drenos cobertos ou tubulares são os mais recomendados para o controle do lençol freático.

Em projetos com drenos cobertos, problemas relacionados ao entupimento dos tubos são de suma importância, uma vez que acarreta baixa eficiência de operação do sistema. A maneira usual de se evitar que esse fato ocorra, consiste na colocação de material de alta condutividade hidráulica entre o solo e o dreno, com funções de impedir o carreamento de partículas e facilitar a entrada de água (Willardson, 1974).

O projeto de drenagem tem, por objetivo principal, apresentar condições de escoamento para a água acumulada em certo local mas, às vezes, tem-se dificuldades naturais de se construir um dreno com camada filtrante adequada às condições locais, pelo fato de não se poder contar com areia de granulometria ideal. Essas dificuldades naturais, somadas aos problemas de projeto e, principalmente, de execução de drenos com areia granulometricamente correta, provocam freqüentes distorções acarretando baixo índice de confiabilidade no sistema drenante. Tais fatos tornaram conveniente a utilização de materiais sintéticos filtrantes de características constantes e fácil utilização. Na prática, observa-se que materiais desse tipo podem conferir ao dreno um alto grau de confiabilidade quanto ao seu desempenho. Ademais, são de fácil manuseio, de aplicação bastante simples (diminuindo substancialmente o tempo de execução) e são de custo comparativamente pequeno (Rhodia, 1982).

Pesquisas têm demonstrado que a utilização de envelopes de cascalho fino e areia grossa tem fornecido bons resultados; todavia, aspectos relacionados à homogeneidade do material, mão-de-obra com transporte e instalação, dentre outros, têm-se apresentado como fatores limitantes à sua utilização.

Devido à escassez de pesquisas relativas ao desempenho de envoltórios de material sintético, ao surgimento de novos geotêxteis e por se reconhecer a necessidade de um estudo comparativo na eficiência desses materiais, desenvolveu-se este trabalho com o objetivo de se estudar, comparativamente, o desempenho de drenos com diferentes tipos de envoltórios sintéticos e minerais, nas condições de fluxo não-permanente.

\section{MATERIAL E MÉTODOS}

O experimento foi conduzido no período de 21.10 .98 a 21.01.99, na área experimental do Laboratório de Hidráulica e Irrigação da UFC - Fortaleza, CE. Construiu-se um modelo físico de laboratório, constituído por oito tanques de drenagem, revestidos de argamassa e internamente impermeabilizados, cada um com 1,5 m de altura, 2,0 $\mathrm{m}$ de largura e 1,5 $\mathrm{m}$ de comprimento.

$\mathrm{Na}$ parte interna de cada tanque foi instalado um dreno tubular corrugado, flexível, de PVC (DN 65), abertura de entrada de água igual a $11,4 \mathrm{~cm}^{2} \mathrm{~m}^{-1}$, na profundidade de $1,10 \mathrm{~m} \mathrm{em}$ relação à parte superior do tanque. No ponto de descarga dos drenos adaptou-se um tubo de PVC rígido de $0,30 \mathrm{~m}$ de comprimento, com tampa roscável. Duas entradas de água foram colocadas junto ao fundo da parede frontal, ambas ligadas a um registro, permitindo o enchimento individual de cada tanque. Fez-se a vedação de uma das extremidades do tubo de drenagem, de forma a assegurar a entrada de água somente através dos orifícios do tubo.

Para acompanhar a variação da profundidade do lençol freático em relação ao tempo de drenagem, foram instalados, em cada tanque, quatro poços de observação em linha perpendicular ao eixo do dreno, na profundidade de $1,20 \mathrm{~m} \mathrm{e}$ afastados da interface solo-dreno nas distâncias de 0,05, 0,25, 0,55 e $0,95 \mathrm{~m}$.

As Figuras 1 e 2 descrevem detalhes do modelo físico experimental e a Tabela 1 mostra as características físicas do material de substrato colocado nos tanques de drenagem. Procurou-se utilizar um material o mais homogêneo possível para minimizar o erro de se compor uma nova variável. Portanto, quando da colocação do material nos tanques de drenagem, o mesmo foi seco ao ar e passado em peneira de $5,0 \mathrm{~mm}$, para proporcionar melhor uniformização. No intuito de evitar problemas com acamamento do material de solo, fez-se um umedecimento leve em camadas de $0,10 \mathrm{~m}$, quando do preenchimento dos tanques de drenagem, ocasião em que se procurou obter densidade de solo semelhante em todos os tanques de drenagem, em cada bloco ou repetição.

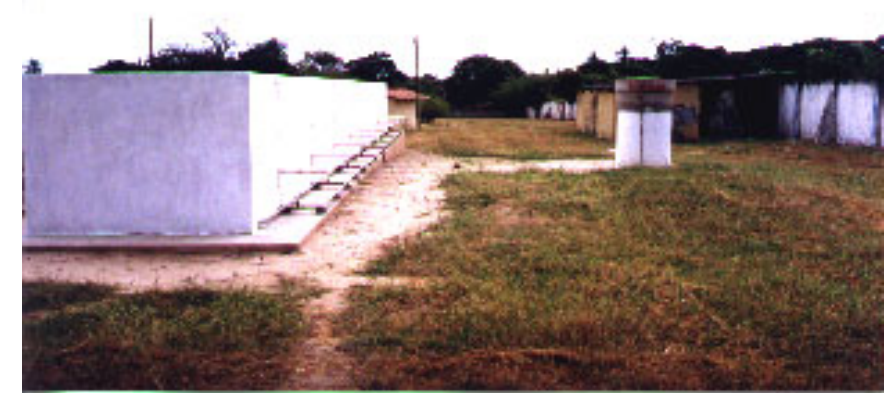

Figura 1. Vista geral dos tanques de drenagem 
Tabela 1. Características físicas do substrato de solo utilizado nos tanques de drenagem

\begin{tabular}{|c|c|c|c|c|c|c|c|c|}
\hline \multicolumn{4}{|c|}{ Composição Granulométrica $\left(\mathrm{g} \mathrm{kg}^{-1}\right)$} & \multirow{2}{*}{ Classificação Textural } & \multicolumn{2}{|c|}{ Densidade $\left(\mathrm{kg} \mathrm{m}^{-3}\right)$} & \multicolumn{2}{|c|}{ Umidade $(\%)$} \\
\hline Areia Grossa & Areia Fina & Silte & Argila & & Solo & Partículas & $1 / 3 \mathrm{~atm}$ & $15 \mathrm{~atm}$ \\
\hline 780 & 180 & 20 & 20 & Areia & 1520 & 2800 & 2,60 & 1,10 \\
\hline
\end{tabular}

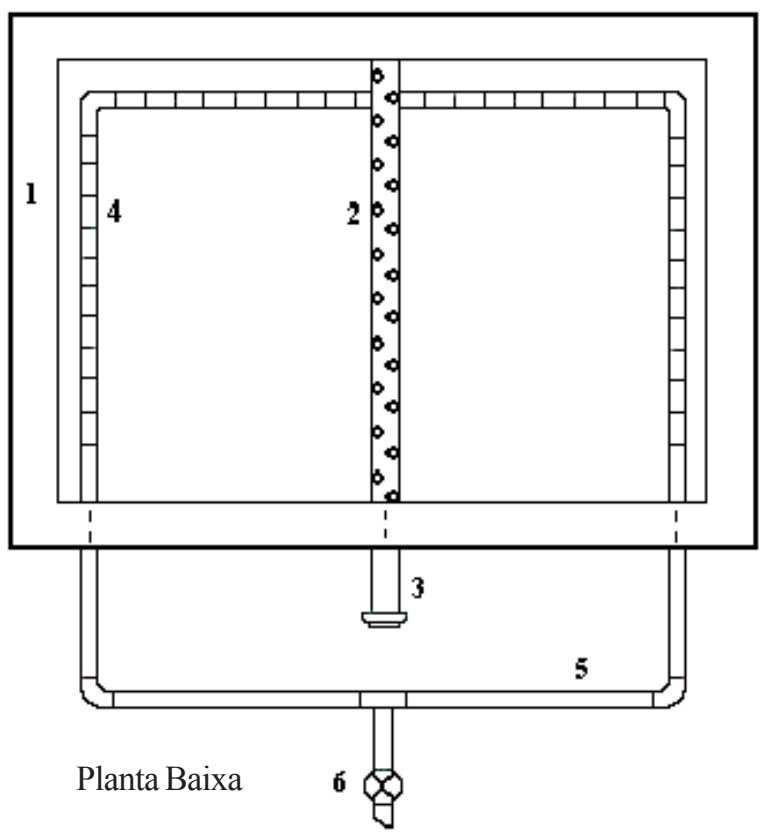

Figura 2. Planta baixa de um dos tanques

Os tratamentos consistiram de oito tipos de envoltório:

Tratamento 1: ausência de envoltório

Tratamento 2: envelope de brita $\mathrm{n}^{\circ} 1 \mathrm{com} 0,15 \mathrm{~m}$ de espessura

Tratamento 3: envelope de brita $\mathrm{n}^{\circ} 1 \mathrm{com} 0,10 \mathrm{~m}$ de espessura

Tratamento 4: envelope de brita $\mathrm{n}^{\circ} 1 \mathrm{com} 0,05 \mathrm{~m}$ de espessura

Tratamento 5: geotêxtil Bidim (OP-20)

Tratamento 6: geotêxtil Bidim (OP-30)

Tratamento 7: geotêxtil XT-2

Tratamento 8: geotêxtil XT-4.

$\mathrm{O}$ delineamento experimental foi em blocos completos casualizados, constando de oito tratamentos e três repetições, em que a posição de cada tratamento nos tanques foi determinada aleatoriamente, conforme prescreve o delineamento. Desta forma, os drenos foram reinstalados e mudados de posição a cada repetição. A Tabela 2 mostra a distribuição dos tratamentos nos tanques de drenagem em cada repetição.

Tabela 2. Distribuição dos tratamentos nos tanques de drenagem

\begin{tabular}{|c|c|c|c|c|c|c|c|c|}
\hline \multirow{2}{*}{ Blocos } & \multicolumn{8}{|c|}{ Tanques de Drenagem } \\
\hline & A & B & $\mathrm{C}$ & D & $\mathrm{E}$ & $\mathrm{F}$ & $\mathrm{G}$ & $\mathrm{H}$ \\
\hline I & 7 & 1 & 3 & 5 & 2 & 6 & 4 & 8 \\
\hline II & 7 & 1 & 5 & 4 & 6 & 8 & 2 & 3 \\
\hline III & 5 & 6 & 1 & 7 & 3 & 4 & 8 & 2 \\
\hline
\end{tabular}

As variáveis-resposta utilizadas para se testar os tratamentos consistiram da lâmina drenada num tempo de $30 \mathrm{~min}$, da fração areia carreada após este tempo de drenagem, do desempenho hidráulico dos drenos com base no cálculo da resistência de entrada ao fluxo e da relação entre vazão e carga hidráulica a $0,55 \mathrm{~m}$ da interface solo-dreno.

A coleta de dados foi realizada em três períodos, sendo o primeiro entre 03.09 .98 e 25.09.98, o segundo entre 24.11 .98 e
03.12.98 e o terceiro entre 12.01 .99 e 21.01 .99 . Inicialmente, os tanques de drenagem receberam uma recarga com os drenos fechados, no intuito de se elevar o lençol freático para próximo da superfície do solo. Atingida essa condição, a recarga foi suspensa e o dreno aberto, procedendo-se às referidas medições. Considerou-se como tempo igual a zero, decorridos cinco segundos após a abertura do dreno.

As lâminas drenadas em cada um dos tratamentos foram obtidas pelo método volumétrico direto, conforme Bernardo (1987) e estimadas a partir de equações ajustadas com os dados de vazão e tempo de drenagem. Equações do tipo exponencial foram as que melhor se ajustaram às variáveis em análise; portanto, com base nas equações obtidas, estimou-se o volume drenado durante a realização do teste, calculando-se a área sobre a curva vazão versus tempo de drenagem. A lâmina de drenagem, por conseguinte, era obtida pela razão entre volume drenado e área superficial de cada tanque.

Para obtenção do carreamento da fração areia, todas as medições eram realizadas em recipientes exclusivos e numerados para que o conteúdo de cada recipiente fosse passado através de uma peneira com aberturas de $0,053 \mathrm{~mm}$, para separar a fração areia e determinar a quantidade de solo carreado para o dreno. As partículas retidas foram postas a secar ao ar livre e, em seguida, pesadas em balança com precisão de $0,01 \mathrm{~g}$.

A resistência de entrada foi calculada através da seguinte relação:

$$
\mathrm{r}_{\mathrm{ent}}=\frac{\mathrm{h}_{\mathrm{ent}}}{\mathrm{Q} \cdot \mathrm{C}^{-1}}
$$

sendo:

$\mathrm{r}_{\text {ent }}$ - resistência de entrada, $\mathrm{L}^{-1} \mathrm{~T}$

$\mathrm{h}_{\mathrm{ent}}$ - carga hidráulica de entrada, $\mathrm{L}$

$\mathrm{Q}^{\text {ent }}$ - descarga do dreno lateral. $\mathrm{L}^{3} \mathrm{~T}^{-1}$

C - comprimento do dreno lateral, $\mathrm{L}$

Quando se trata de avaliar a eficiência de drenos tubulares, a componente de entrada constitui um parâmetro importante, tanto como valor independente como parte da perda total da carga hidráulica, tornando possível descrever-se a eficiência por meio da carga hidráulica de entrada $\left(\mathrm{h}_{\text {ent }}\right)$ e da resistência de entrada $\left(\mathrm{r}_{\text {ent }}\right)$ conforme citam Dieleman \& Trafford (1976). A carga hidráulica de entrada era obtida junto ao poço de observação instalado à distância de $0,05 \mathrm{~m}$ da interface solodreno.

As medidas de carga hidráulica de entrada $\left(\mathrm{h}_{\text {ent }}\right)$ em função da descarga por unidade de comprimento $\left(\mathrm{q}_{\mathrm{u}}\right)$ foram utilizadas por regressão linear, para avaliar os valores de resistência de entrada $\left(\mathrm{r}_{\text {ent }}\right)$; tendo em vista a relação de tendência linear entre os referidos parâmetros, o coeficiente angular da reta representa teoricamente a resistência de entrada.

$\mathrm{Na}$ análise da relação entre vazão e carga hidráulica a $0,55 \mathrm{~m}$ da interface solo-dreno, nos diversos tempos de drenagem, 
ajustaram-se, por meio de regressão, equações matemáticas que melhor descrevessem o comportamento entre as variáveis. $\mathrm{Na}$ escolha do melhor modelo utilizaram-se, como critério de escolha, o valor do coeficiente de determinação $\left(\mathrm{R}^{2}\right)$ e as respectivas análises de variância dos modelos testados.

As análises de variância e os testes de comparação múltipla foram processados pelo programa de computação SANEST (Sistema de Análise Estatística) ESALQ-USP.

Procedeu-se a uma análise de variância individual para cada uma das variáveis analisadas, sendo as médias comparadas pelo teste de Tukey, a níveis de 5 e 1\% de probabilidade. $\mathrm{Na}$ análise de variância, os tratamentos foram comparados pelo teste $\mathrm{F}$, considerando-se um nível mínimo de significância de 5\% de probabilidade (Gomes, 1990).

\section{RESULTADOS E DISCUSSÃO}

A Tabela 3 mostra o resumo da análise de variância para lâmina de drenagem $(\mathrm{mm})$, carreamento de solo $(\mathrm{g})$, resistência de entrada $\left(\mathrm{d} \mathrm{m}^{-1}\right)$ e relação entre vazão e carga hidráulica $\left(\mathrm{L} \mathrm{min} \mathrm{m}^{-1} \mathrm{~cm}^{-1}\right)$ enquanto a Tabela 4 indica as médias para cada parâmetro analisado, além do teste de Tukey, para médias de tratamentos.

Observa-se, com base nos resultados das análises estatísticas que, embora as variáveis lâmina de drenagem e resistência de entrada tenham apresentado tendência diferenciada em relação aos tratamentos, tais discrepâncias não foram estatisticamente significativas a nível de 5\%.

A variável resistência de entrada, com valor de $\mathrm{F}$ igual a 1,88 , apresentou resultado significativo a nível de $14,9 \%$, valor este que representa a probabilidade de erro, ao se rejeitar a hipótese de nulidade, enquanto a variável lâmina de drenagem, com valor de F igual a 0,6182, apresenta probabilidade de erro muito elevada $(73,4 \%)$ ao se rejeitar a hipótese de nulidade. Conforme Gomes (1990) uma das explicações para $\mathrm{F}<1$, 0 , é a de que o resíduo inclua alguma causa importante de variação, que foi controlada mas não foi isolada na análise de variância. A existência de correlação que não tenha sido levada em conta também é uma explicação dessa anomalia.
O envoltório constituído pela manta de poliéster bidim OP-20, apresentou o maior valor de lâmina drenada, com acréscimo de $14 \%$ em relação ao tratamento com menor lâmina drenada (bidim OP-30). Tal valor, no entanto, não apresentou diferença estatística significativa em relação aos demais tratamentos, a nível de significância de 5\%. Embora no presente experimento não se tenha realizado análise econômica referente à instalação dos envoltórios, um levantamento preliminar demonstra que a instalação de envoltórios constituídos por brita tem um custo superior ao de envoltórios de manta geotêxtil, em face do maior custo com o transporte e instalação propriamente dita; além disso, as mantas demonstram vantagens em relação a materiais granulares quanto ao aspecto de homogeneidade do material de fabricação. Considerando-se tais aspectos e face à obtenção de desempenhos semelhantes no que se refere à lâmina de drenagem, na presente pesquisa o geotêxtil Bidim OP-20 mostrou-se como a melhor opção.

Em pesquisa sobre desempenho de envoltórios na eficiência da drenagem de um solo com drenos tubulares e utilizando, como variável-resposta, o parâmetro lâmina drenada, Pereira (1988) verificou que o filtro de pedregulho e areia foi o envoltório que apresentou melhor desempenho porém, considerando-se a praticidade de instalação e a economia de mão-de-obra e de transporte, o geotêxtil Bidim OP-30 apresentou-se como a melhor opção. Além desses envoltórios, o autor utilizou, também, os tratamentos constituídos por envelopes de brita com espessuras de 0,025, 0,05 e $0,10 \mathrm{~m}$, além do geotêxtil Ober 851 .

Os tratamentos com brita apresentaram os maiores valores quanto a carreamento de areia, embora não diferindo estatisticamente a nível de $5 \%$ de significância. Observou-se, nesses tratamentos, relação inversa entre carreamento de areia e espessura do envoltório, cujos resultados podem ser explicados pela redução na velocidade da água, face ao aumento da espessura do envoltório que circunda o dreno, conforme atesta Cruciani (1989); já o tratamento envoltório de brita, com 0,15 m de espessura, não diferiu estatisticamente dos demais tratamentos.

Tabela 3. Análise de variância dos parâmetros analisados

\begin{tabular}{lcrrrr}
\multicolumn{1}{c}{ Parâmetro } & G.L. & S.Q. & Q.M & Valor F & P $>$ F \\
\hline Lâmina de drenagem & 7 & 1402,72586 & 200,38941 & 0,6182 & 0,73398 \\
Carreamento de solo & 7 & 4204,18951 & 600,59850 & 7,8385 & 0,00086 \\
Resistência de entrada & 7 & 0,0001057 & 0,0000151 & 1,8803 & 0,14894 \\
Relação entre vazão e carga hidráulica & 7 & 6,6677799 & 0,9525400 & 2,2244 & 0,09607 \\
\hline
\end{tabular}

Tabela 4. Comparação das médias* de tratamentos pelo teste de Tukey

\begin{tabular}{|c|c|c|c|c|}
\hline Tratamento & $\begin{array}{l}\text { Lâmina de } \\
\text { Drenagem }\end{array}$ & $\begin{array}{c}\text { Carreamento } \\
\text { de Solo }\end{array}$ & $\begin{array}{l}\text { Resistência } \\
\text { de Entrada }\end{array}$ & $\begin{array}{l}\text { Relação Entre Vazão e } \\
\text { Carga Hidráulica }\end{array}$ \\
\hline Bidim OP-20 & 205,86 a & $0,075 \quad b$ & $0,00497 \quad \mathrm{a}$ & $1,536 \mathrm{ab}$ \\
\hline Brita com $0,10 \mathrm{~m}$ de espessura & 204,83 a & 29,828 a & $0,00467 \quad \mathrm{a}$ & $1,706 \mathrm{ab}$ \\
\hline Sem envoltório & 204,62 a & $1,288 \quad b$ & 0,01023 a & $0,950 \mathrm{~b}$ \\
\hline Brita com $0,15 \mathrm{~m}$ de espessura & 202,72 a & $9,607 \mathrm{ab}$ & 0,00320 a & 2,867 a \\
\hline XT-4 & 201,35 a & $0,079 \mathrm{~b}$ & 0,00430 a & $1,484 \mathrm{ab}$ \\
\hline Brita com $0,05 \mathrm{~m}$ de espessura & 200,26 a & 33,325 a & $0,00790 \quad \mathrm{a}$ & $1,258 \mathrm{ab}$ \\
\hline XT-2 & 199,13 a & $0,167 \quad b$ & $0,00623 \mathrm{a}$ & $1,488 \mathrm{ab}$ \\
\hline OP-30 & 180,54 a & $0,082 \mathrm{~b}$ & 0,00560 a & $1,409 \mathrm{ab}$ \\
\hline
\end{tabular}

Médias seguidas pela mesma letra na vertical não diferem entre si em nível de 5\% de probabilidade 
Os resultados apresentados em base aos tratamentos constituídos por brita, comprovam que esses envoltórios não têm a função de filtro, conforme se observa pelo maior carreamento de areia ao se compará-lo com o tratamento sem envoltório. Ao contrário, esse tipo de envelope proporciona maior arraste de material.

Os envoltórios de mantas sintéticas testados nesta pesquisa, proporcionaram ótimo desempenho quanto à sua função seletiva, mostrando que os mesmos podem ser usados indistintamente como filtros.

Em conformidade com os critérios estabelecidos por Wesseling \& van Someren (1970) e Dieleman \& Trafford (1976) o desempenho hidráulico de todos os sistemas drenantes, diferenciados por cada um dos envoltórios testados, pode ser considerado "muito bom", com base nos valores do parâmetro resistência de entrada. Tais valores podem ser explicados em razão do material de solo colocado nos tanques de drenagem, além dos envoltórios testados apresentarem elevada condutividade hidráulica.

Embora os valores de resistência de entrada só tenham apresentado diferença estatística significativa a nível de $14,9 \%$ em relação aos tratamentos testados, observa-se que o tratamento sem envoltório apresentou elevado valor, se comparado aos demais, demonstrando a importância do uso de envoltórios em drenos tubulares. Resultado semelhante foi observado por Silva et al. (1997). O envoltório constituído por brita com $0,15 \mathrm{~m}$ de espessura foi o que apresentou melhor desempenho, o que se justifica tendo em vista o raio efetivo do dreno; por outro lado, as mantas sintéticas geotêxteis XT-4 e OP-20 apresentaram melhores desempenhos, se comparadas às demais mantas testadas. Antonini (1989) utilizando modelo físico de laboratório para fins de estudo de desempenho com drenos sem envelope e com envelope sintético, observou que o envoltório constituído por Bidim OP-20 foi mais eficiente que a areia grossa para diminuir a resistência de entrada da água nas aberturas do dreno, enquanto Soares (1996) avaliando a eficiência de linhas de drenos laterais constituídos por manilhas de barro com envoltórios de seixo rolado e areia grossa, constatou avarias no sistema, com base nos valores de resistência de entrada.

O desempenho da vazão dos drenos nos diferentes tratamentos em relação à variação da carga hidráulica a $0,55 \mathrm{~m}$ da interface solo-dreno, é representado na Figura 3, na qual são mostrados, também, as curvas de três dos oito tratamentos. Ajustaram-se funções do tipo linear aos pontos observados em todos os tratamentos. Dieleman \& Trafford (1976) justificam a linearidade quando o lençol freático desce até próximo do nível dos drenos.

A um nível de significância de 5\% na comparação entre as médias, o tratamento brita, com $0,15 \mathrm{~m}$ de espessura, apresentou o melhor desempenho, diferindo estatisticamente apenas do tratamento sem envoltório. Excluindo-se o tratamento brita com espessura de $0,15 \mathrm{~m}$, os demais tratamentos não diferiram estatisticamente mas, para os tratamentos constituídos por geotêxteis de manta de poliéster, embora não tenham sido detectadas diferenças significativas, verificou-se que o envoltório de bidim OP-20 apresentou tendência de melhor desempenho, comparado aos demais.
(A)

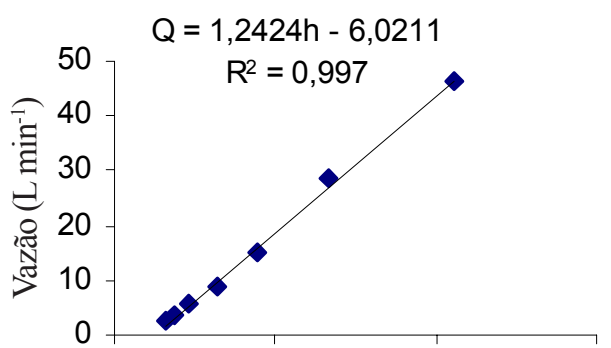

(B)

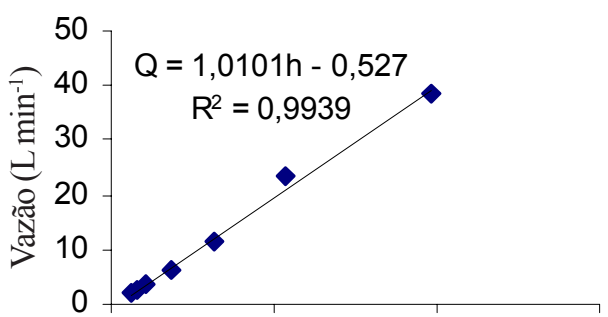

(C)

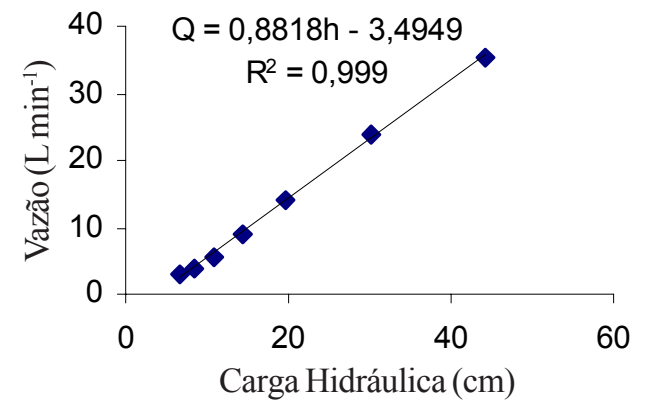

Figura 3. Relação funcional entre vazão do dreno e carga hidráulica para os tratamentos geotêxtil (A)XT-2, (B) OP-20 e (C) sem envoltório, respectivamente

\section{CONCLUSÕES}

1. Os sistemas drenantes apresentaram desempenho hidráulico considerado "muito bom", com base nos valores do parâmetro resistência de entrada. Uma resistência maior à entrada do fluxo de água foi observada no tratamento sem envoltório. $\mathrm{O}$ tratamento sem envoltório, com menor valor de coeficiente angular obtido por meio de ajuste linear entre vazão e carga hidráulica a $0,55 \mathrm{~m}$ da interface solo-dreno, apresentou tendência diferenciada dos demais tratamentos, reafirmando a importância da utilização de envoltórios em drenos tubulares.

2. As lâminas drenadas não diferiram estatisticamente a nível de $5 \%$ de probabilidade, mas o geotêxtil bidim OP-20 apresentou o maior valor de lâmina drenada $(205,86 \mathrm{~mm})$ com acréscimo de 14\% em relação ao tratamento de menor lâmina drenada - bidim OP-30 (180,54 mm).

3. A variável-resposta carreamento de solo demonstrou que as mantas sintéticas apresentaram ótimo desempenho como filtro, não diferindo estatisticamente a nível de $5 \%$ de significância.

4. Os tratamentos com brita apresentaram os maiores valores quanto a carreamento de solo, embora não diferindo estatisticamente a nível de 5\% de significância. Demonstrou-se, também, com base nesses tratamentos, a influência da espessura do envoltório, face à relação inversa desta com o parâmetro carreamento de solo. 
5. Os valores de lâminas drenadas nos tratamentos com geotêxteis, quando comparados com os tratamentos com brita, indicam que os geotêxteis provavelmente possuem elevados valores de condutividade hidráulica.

\section{AGRADECIMENTOS}

Os autores agradecem à Fundação Cearense de Amparo à Pesquisa - FUNCAP, pelos recursos financeiros de apoio à pesquisa.

\section{LITERATURA CITADA}

Antonini, J.C.A. Desempenho dos drenos sem envelope e com envelope sintético em relação ao dos drenos com envelope de material mineral, submetidos ao regime de escoamento não-permanente. Viçosa: UFV, 1989. 58p. Dissertação Mestrado

Bernardo, S. Manual de Irrigação. Viçosa: Imprensa Universitária, 1987.488p.

Cruciani, D.E. A drenagem na agricultura. 4. ed. São Paulo: Nobel, 1989, 337p.

Dieleman, P.J.; Trafford, B.D. Drainage testing. Rome: FAO, 1976. FAO. Irrigation and Drainage, Paper 28

Gomes, F.P. Curso de estatística experimental. 13. ed. São Paulo: Nobel, 1990. 486p.
Hillel, D. Solo e água, fenômeno e princípios físicos. Porto Alegre: UFRGS, 1970. 231p.

Lamster, E.C. Programa nacional de aproveitamento racional de várzeas - Provárzeas Nacional. Informe Agropecuário, Belo Horizonte, v.6, n.65, p.3-8, 1980.

Pereira, A.A.A. Desempenho de envoltórios na eficiência da drenagem de um solo com drenos tubulares. Piracicaba: ESALQ/USP, 1988. 100p. Dissertação Mestrado

Rhodia. Drenos, princípios básicos e estrutura de drenagem. São Paulo: Rhodia, 1982. 35p.

Silva, V.P.; Srinivasan, V.S.; Azevedo, C.A.V. Avaliação estatística do desempenho de sistemas drenantes com relação à resistência e carga hidráulica de entrada. In: Congresso Brasileiro de Engenharia Agrícola, 26, 1997, Campina Grande. Resumos... Campina Grande: Sociedade Brasileira de Engenharia Agrícola/UFPB, 1997. CD Rom

Soares, O.H.D. Monitoramento do processo de recuperação de um solo aluvial sódico em condições de drenagem subterrânea. Fortaleza: UFC, 1996. 106p. Dissertação Mestrado

Wesseling, J.; van Someren, C.L. Drainage materials: Provisional report of the experience gained in The Netherlands. In: Irrigation and Drainage. Rome: FAO, Paper 9. 1970. p.55-83.

Willardson, L.S. Envelope material. In: van Schilfgaarde, Journal Drainage for Agriculture. Madison: American Society of Agronomy, 1974. p.179-196. 